\title{
Personalia
}

\section{Mykola Lebovka's 60th birthday}

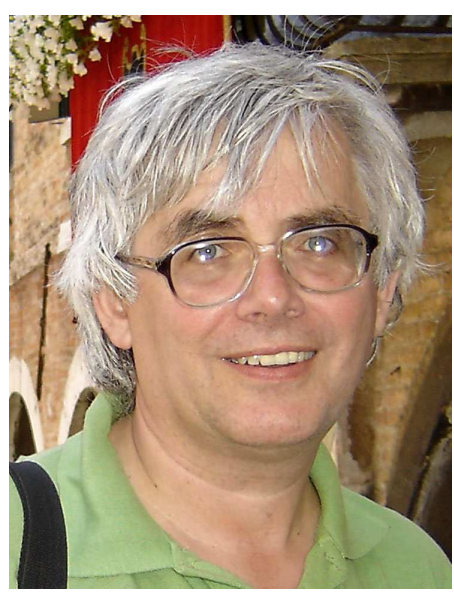

May 15 this year was the $60^{\text {th }}$ birthday of Mykola Lebovka, an outstanding Ukrainian scientist in the field of physical chemistry of condensed matter, Doctor Habilitus in Physics and Mathematics, professor, head of the Department of Physical Chemistry of Disperse Minerals at F.D. Ovcharenko Institute of Biocolloidal Chemistry, National Acad.Sci. of Ukraine.

Mykola Lebovka spent his childhood and youth, including the period of his study, in Kyiv. Since childhood, he was craving for knowledge, and his parents trained him to insistent work. He was especially interested in history, physics and mathematics. The final two years of his secondary education he studied in the specialized school of physics and mathematics. In 1976 Mykola Lebovka graduated from Taras Shevchenko National University of Kiev with Honour Diploma of the Physics Faculty in speciality 'Optics and Spectroscopy'. He defended his Ph.D. thesis in molecular physics entitled 'Structure of Boundary Water Layers' in 1986, and in 1995 he got his Dr.Hab. both in colloidal and membrane chemistry and in molecular physics for 'Distribution of Random Fields in Heterogeneous Systems'.

Mykola Lebovka is the author of over 300 scientific publications in peer reviewed journals, which are highly cited all over the world, and of a number of articles in monographs. The range of his scientific activities is very wide. Currently, his major scientific interests are related to physics and chemistry of soft condensed matter and colloids, statistical and computational physics, and application of pulsed electric fields (PEF) for treatment of plant tissues, including electroporation of cell membranes, killing of pathogenic bacteria and activation of yeasts. He is both a talented experimentalist and high-level theorist. His first experimental studies are related to the investigation of the behaviour of water vapours and aqueous systems using NMR spectroscopy technique. He made an important contribution into NMR application for the studies of liquid crystals and the structure of liquid systems near the interface and in the spatially-confined systems. The theoretical works by Mykola Lebovka are related to the application of computer simulation methods for investigation of the processes of aggregation in colloidal systems and for the study of the problem of percolation in composite systems filled with highly anisotropic particles (plates or rods). His computer simulation studies have become a basis for investigations of a whole series of different composite systems filled with nanotubes. M. Lebovka discovered the effect of electrical memory in liquid crystal composites filled with organo-modified montmorillonite and multilayered carbon nanotubes. A substantial part of experimental studies, carried out by M. Lebovka, is related to the investigation of the principles of control of the permeability of biological cell membranes using pulsed electric fields. The results of these studies permitted to accelerate the processes of drying the food materials and to enhance the extraction of useful substances from the tissues of plant origin.

Common scientific interests unite Mykola Lebovka with researchers from different countries. He frequently participates in various international projects of research collaboration, as well as in organizing scientific conferences, schools, seminars, etc. M. Lebovka is a member of Ukrainian Physical Society and Scientific Council for Physics of Soft Matter (Physics and Astronomy Department of the National Academy of Sciences of Ukraine). He represents Ukraine in the Council of Association International pour l'Étude des Argiles (AIPEA, International Association for the Study of Clays).

M. Lebovka is a member of several Specialized Scientific Councils for Ph.D. and D.Hab. degrees. He contributes a lot of efforts into eductional activities and training of young scientists. During many years 
he was lecturing in a number of key Kiev universities, including National University of Kiev-Mohyla Academy, National Technical University of Ukraine 'Kiev Polytechnic Institute' and National Aviation University of Ukraine, where he was delivering such special subjects as Software Instruments for Solving Physical Problems, Simulation of Physical and Biological Media, Physics of Disordered Media, Fractals in Natural Sciences, etc. Nowadays M. Lebovka continues his educational activities at Applied Physics Department of the National Aviation University of Ukraine and at Molecular Physics Department of Taras Shevchenko National University of Kiev. M. Lebovka pays much attention to training the postgraduate students. All of his postgraduates succesfully get their Ph.D. degrees under his guidance.

As a member of a research team, in 2011 Mykola Lebovka was awarded a State Prize of Ukraine in Science and Engineering for Quantum Effects and Structural Self-Organization in Novel Multi-Functional Nano-Materials.

Colleagues and collaborators cordially greet Mykola Lebovka with his anniversary and wish him to stay in good health and get inspiration for successful implementation of his new creative concepts. 